\title{
Work-related well-being of South African hospital pharmacists
}

\begin{abstract}
Authors:
Sebastiaan Rothmann ${ }^{1}$

Madeleine Malan ${ }^{2}$

Affiliations:

${ }^{1}$ School of Behavioural

Sciences, North-West

University, Vanderbijlpark,

South Africa

${ }^{2}$ Workwell Research Unit, North-West University,

Potchefstroom, South Africa

Correspondence to:

Sebastiaan Rothmann

Email:

ian@ianrothmann.com

Postal address:

PO Box 1174, Vanderbijlpark

South Africa

Dates:

Received: 24 Feb. 2010

Accepted: 14 Mar. 2011

Published: 04 July 2011

How to cite this article:

Rothmann, S., \& Malan,

M. (2011). Work-related

well-being of South African

hospital pharmacists.

SA Journal of Industrial

Psychology/SA Tydskrif vir

Bedryfsielkunde, 37(1), Art.

\#895, 11 pages. doi:10.4102/

sajip.v37i1.895

Note:

The material described in this article is based upon work supported by the National Research Foundation under Grant number 2053344
\end{abstract}

C) 2011. The Authors.

Licensee: AOSIS

OpenJournals. This work

is licensed under the

Creative Commons

Attribution License.
Orientation: Hospital pharmacists in South Africa are experiencing increased stress because of the high demand for their services, a lack of resources in hospital pharmacies, and the shortage of pharmacists in South Africa.

Research purpose: The objective of this study was to investigate whether job stress and coping strategies could predict the work-related well-being (burnout and work engagement) of hospital pharmacists in South Africa.

Motivation for the study: Information about the work-related well-being and coping strategies of hospital pharmacists could be used to plan individual and organisational interventions which can be used to retain them and to manage their well-being and performance.

Research design, approach and method: A survey design was used. A stratified random sample $(N=187)$ of pharmacists in South African hospitals was studied. The Maslach Burnout Inventory - Human Services Survey, Utrecht Work Engagement Scale, Pharmacist Stress Inventory and the COPE questionnaire were administered.

Main findings: The results showed that job related stress and three coping strategies (approach coping, avoidant coping, and turning to religion) predicted burnout and work engagement of South African hospital pharmacists.

Practical/managerial implications: Job stressors that are in the main responsible for the unfavourable work environment and that lead to the development of burnout amongst hospital pharmacists should be addressed. It is also important to enhance the coping capabilities of the hospital pharmacists.

Contribution/value-add: The findings of this study provide insight into the factors impacting on the work-related well-being of hospital pharmacists in South Africa.

\section{Introduction}

Pharmacists have to cope with the demands that arise from fulfilling various roles, as well as with increased pressures such as managed health care and primary health care. Tracking and addressing the work-related well-being of pharmacists is necessary because of its impact on the standard of pharmacy services (Gupchup, Singhal, Dole \& Lively, 1998). The work-related well-being of pharmacists can be studied in terms of negative outcomes (e.g. distress) and positive outcomes (e.g. eustress; see Nelson \& Simmons, 2003). Distress is defined as a negative psychological response to a stressor, as indicated by the presence of negative psychological states (e.g. exhaustion and depersonalisation). Eustress refers to a positive psychological response to a stressor as indicated by the presence of positive psychological states (e.g. vigour and dedication; Nelson \& Simmons, 2003).

English (2001) reports that the pharmaceutical profession faces an acute shortage of pharmacists. Pharmacists are responsible for handling both the increased demand for prescription medication and the need for clinical pharmacy services (Rothmann \& Malan, 2007). Unless the stress that pharmacists experience as a result of their profession is reduced, their work may be endangering their physical and mental health, and compromise patient safety. Job-related stress might lead to burnout and low work engagement, which could result in high staff turnover (Cavanaugh, 1989; Mott, Doucette, Gaither, Pedersen \& Schommer, 2004).

Internationally and in South Africa pharmacists are experiencing an increased demand for their services due to the general increase in the age of the population and the subsequent increased use 
of prescription medication (Boschmans, 2008; Knapp, 2002; Knapp \& Cultice, 2007). According to Knapp (2002), the use of individualised drug therapy through biotechnology may increase the need for drug therapy management further. Linked to the increased demand for pharmacist services are reports that the number of pharmacists in the United States has not kept pace with increased demand (Health Resources \& Service Administration, 2000). The same trend is occurring in South Africa, especially because many pharmacists are leaving the country to pursue careers as pharmacists abroad (Matowe, Duwiejua \& Norris, 2004). The imbalance between supply and demand has affected the amount and type of work pharmacists perform and subsequently resulted in jobrelated stress (Rothmann \& Malan, 2007). The interaction between work environments and the amount and type of work pharmacists perform can influence pharmacists' workrelated well-being (burnout and work engagement; Health Resources \& Services Administration, 2000).

Burnout has been consistently linked with health problems as well as with organisational consequences such as increased turnover of staff, increased intention to leave, negative work attitudes, and reduced levels of performance (Brotheridge \& Grandey, 2002). Rothmann, Rothmann, Van Rensburg and Malan (2000) regard burnout as one of the key factors that contribute to the impairment of pharmacists. This is especially important because pharmacists work in an environment where drugs are available and impairment of pharmacists and the resulting misuse of drugs may affect their judgement during day-to-day practice. Hospital pharmacists in South Africa, especially in the public sector, are confronted with various stressors, including high workload, shortage of staff, and lack of medicine (Pretorius, 2001; Rothmann \& Malan, 2007). The Disciplinary Committee of the South African Pharmacy Council expressed their concern regarding the workload of pharmacists in the public sector and stated that it is twice the acceptable norm, which could result in burnout (Beukes, 2002; Rothmann et al., 2000).

Therefore, burnout and its relationship with hospital pharmacists' job stress and coping strategies should be investigated. Furthermore, based on the studies of Kahn (1990) and May, Gilson and Harter (2004) it can be expected that burned out individuals will also be less available psychologically (i.e. they will lack physical, emotional, and/ or cognitive resources). Information about the work-related well-being and coping strategies of hospital pharmacists could be used to plan individual and organisational interventions which can be used to retain them and to manage their well-being.

The objective of this study was to investigate whether job stress and coping strategies were related to the burnout and work engagement of hospital pharmacists.

\section{Work-related well-being}

Burnout and work engagement are indicators of the wellness of employees at work, Schaufeli and Bakker (2004) suggest that they could be combined in a model of work-related wellbeing. Based on a theoretical analysis, these authors identify two underlying dimensions of work-related well-being:

1. activation, ranging from exhaustion to vigour

2. identification, ranging from depersonalisation to dedication.

From a theoretical perspective, burnout is characterised by a combination of exhaustion (low activation) and depersonalisation (low identification), whereas engagement is characterised by vigour (high activation) and dedication (high identification). Accordingly, vigour and dedication are considered direct opposites of exhaustion and depersonalisation, respectively.

Burnout is a state of exhaustion, depersonalisation, and low personal accomplishment that occurs in normal individuals (Schaufeli \& Enzmann, 1998). Burnout has been recognised as a serious threat, particularly for employees who work with people (Schaufeli, 2003). It is the end result of consistent unsuccessful attempts at mediating stressors in the environment on the part of the individual (Van Dierendonck, Schaufeli \& Buunk, 1993). According to Schaufeli and Enzmann (1998), burnout can be considered as a particular kind of prolonged job stress. An individual experiences job stress when the demands of the workplace exceed his or her adaptive responses. Burnout is described as a multidimensional, chronic stress reaction that consists of three dimensions, namely emotional exhaustion, depersonalisation and reduced personal accomplishment (Levert, Lucas \& Ortlepp, 2000). Schaufeli (2003) argues that emotional exhaustion and depersonalisation are core components of burnout, whilst personal accomplishment is a personality characteristic.

Emotional exhaustion is considered to be the first stage in the burnout syndrome and central to the experience of burnout (Brotheridge \& Grandey, 2002). Emotional exhaustion is characterised by a lack of energy and a feeling that one's emotional resources are used up. Depersonalisation entails the treatment of clients as objects rather than people. Employees may display a detached attitude, and they may be cynical toward coworkers, clients, and the organisation. According to Cordes and Dougherty (2003), visible symptoms of depersonalisation include the use of derogatory or abstract language, strict intellectualisation of the situation, withdrawal through longer breaks or extended conversations with coworkers, and extensive use of jargon. Depersonalisation is regarded as a (defensive) coping response to emotional exhaustion - an alternative for dealing with emotional exhaustion when other coping resources are not available.

Barnett, Hopkins and Jackson (1986) studied the burnout levels of pharmacists in the United States of America between 1973 and 1983 and found that they experienced moderate levels of burnout. Pharmacists who performed primarily nondistributive duties (e.g. direct patient care, drug information, teaching or research, and management 
or administration) experienced lower levels of burnout than those involved primarily in drug distribution. Gupchup et al. (1998) found in their research that pharmacists in the United States of America experience moderate levels of burnout. Daily demands of the job and dealing with patients, the professional role, counter prescribing and time pressures may contribute to emotional exhaustion and depersonalisation (Gupchup et al., 1998; Willett \& Cooper, 1996). A more recent study on burnout of a small sample of pharmacists in South Africa using the Maslach Burnout Inventory (MBI) indicated that respondents experience low to moderate levels of emotional exhaustion and depersonalisation (Malan, Rothmann \& Rothmann, 2002).

Schaufeli, Salanova, González-Romá and Bakker (2002) describe burnout and work engagement as opposite concepts that should be measured independently with different instruments. Work engagement consists of three dimensions, namely vigour, dedication and absorption. Vigour refers to high levels of energy and mental resilience whilst working as well as a willingness to exert effort and persistence even through difficult situations. Dedication is described as a sense of significance, enthusiasm, inspiration, pride and challenge. Absorption refers to a tendency to be fully concentrated and deeply engrossed in work, whereby time passes quickly and one has difficulty in detaching oneself from work. However, South African studies could not confirm the validity of the absorption dimension (Rothmann, 2005).

\section{Job stress, coping and work-related well-being}

Job stress is defined as the mind-body arousal resulting from physical and, or psychological job demands (Spielberger et al., 2003). The appraisal of a stimulus as threatening leads to anxiety and anger, and the associated activation of the autonomic nervous system. If severe and persistent, the resulting physical and psychological strain may cause adverse behavioural consequences (Spielberger et al., 2003).

Most job-related stress researchers are of the opinion that unfavourable job conditions can affect employee health and well-being (Cooper \& Cartwright, 1994). A stressor is a condition or situation at work that requires an adaptive response on the part of an employee (Jex \& Beehr, 1991). The Spielberger State-Trait (STP) model of job stress (which was used in this study) conceptualises stress as a complex process that consists of three major components, namely (1) sources of stress that are encountered in the work environment, (2) perception and appraisal of a particular stressor by an employee and (3) the feelings that are evoked when a stressor is appraised as threatening (Spielberger, Vagg \& Wasala, 2003). This model was adopted because it categorises stress in terms of severity and frequency of occurrence of specific job demands and pressures and the level of support provided by supervisors, coworkers and organisational policies and procedures.

Job stress could impact on hospital pharmacists' energy at work and their identification with work. Overload
(Landsbergis, 1988), poor collegial support (Golembiewski \& Munzenrider, 1988), role conflict and role ambiguity (Miller, Ellis, Zook \& Lyles, 1990), and lack of feedback (participation in decision-making and autonomy) have been found to impact on the burnout of employees. These factors represent 'demands' on employees (also referred to as job stressors).

Willett and Cooper (1996) attempted to identify the extent and aetiology of stress in community pharmacy as well as the effect it was having on general well-being of pharmacists. Compared to other workers, pharmacists in this study experienced high levels of stress at work, especially from factors intrinsic to their jobs and their management role. These factors included work overload, autonomy and having to perform a variety of tasks as well as the inability to delegate, a perceived lack of influence and role ambiguity. Pharmacists reported significantly higher levels of distress because of relationships with other people, career and achievement worries than other health care workers (Willett \& Cooper, 1996).

Rothmann and Malan (2007) conducted research regarding the job-related stress of hospital pharmacists in South Africa. They found that a lack of resources is the most severe job stressor for hospital pharmacists. Job-resource stressors that showed the highest severity include the unavailability of medicines from suppliers, frequent interruptions, poorly motivated workers who are not doing their job, inadequate salary and insufficient staff to handle the workload, inadequate support by a supervisor, uncooperative attitudes of other health care professionals, and poor or inadequate equipment. Job demands represented the second highest occupational stress factor. Specific stressors in this category that were severe include working overtime and emergency hours, stock control, and dealing with other health care professionals (Rothmann \& Malan, 2007). Pharmacyspecific stressors represented the third highest job-related stress factor. Specific stressors in this category included low payment from debtors including medical aids, payment of creditors, and other pharmacy-specific issues.

Evidence from previous studies (e.g. Mostert \& Rothmann, 2006; Van der Colff \& Rothmann, 2009) showed that significant relationships between burnout, engagement and job-related stress could be expected. In a sample of police officers, Mostert and Rothmann (2006) found that job stress explained a small percentage of the variance in work engagement. However, stress as a result of job demands and a lack of resources predicted burnout (which consisted of exhaustion and cynicism). Van der Colff and Rothmann (2009) found that exhaustion and depersonalisation of nurses were associated with stress due to job demands and a lack of organisational support.

One of the basic issues in the domain of work-related wellbeing concerns coping, or ways in which an individual can attempt to deal with job stressors to ward off aversive strains (Beehr, Johnson \& Nieva, 1995). According to Cordes and 
Dougherty (2003), the availability of coping resources is a relevant buffer in the burnout process because it affects the relationship between the stressors and emotional exhaustion, as well as the relationship between emotional exhaustion and depersonalisation. Lazarus and Folkman (1984) defined coping as the cognitive and behavioural efforts of an individual to manage external and, or internal demands that are appraised as taxing or exceeding the resources of the person. Coping refers to perceptual, cognitive or behavioural responses that are used to manage, avoid or control situations that could be regarded as difficult (Folkman \& Lazarus, 1984).

Folkman and Lazarus (1984) suggested two general types of coping. The first is problem-focused coping: the person finds a method for resolving stress at its source (i.e. tries to stop whatever was posing the harm or threat from occurring). The second is emotion-focused coping: the person feels that the source of the stress must somehow be tolerated, and he or she endeavours to manage or lessen the emotional discomfort associated with the situation. Emotionfocused coping places its emphasis on interpretation of the situation or how the individual attends to it. In addition, Carver, Scheier and Weintraub (1989) proposed a third style of coping, avoidant coping (Carver \& Scheier, 1996). Denial (pretending the stressor is not present or that it is not causing any significant distress), mental disengagement (distracting oneself from thinking about the goal with which the stressor is interfering), and behavioural disengagement (giving up on the goals with which the stressor is interfering) are examples of avoidant coping strategies. Avoidance differs from problem-focused and emotion-focused coping in that avoiding a situation actually removes the person from the stressful situation, whereas problem-focused and emotion-focused coping might help the person manage the stressful situation whilst he or she remains in it (Kowalski \& Crocker, 2001).

Pienaar and Rothmann (2003) suggested four coping strategies:

- approach coping (which includes active coping, planning, and suppression of competing activities)

- social or emotional coping (which includes seeking social support for emotional reasons seeking social support for instrumental reasons, and focus on and venting of emotion)

- avoidant coping (which includes denial, behavioural disengagement and mental disengagement)

- turning to religion.

Alsoofi, Al-Heeti and Alwashli (2000) found a significant correlation between ways of coping and burnout. When a problem-solving (approach) coping strategy is used, the individual will tend to achieve his or her goals, which will enhance work engagement (Rothmann, 2005). By contrast, when an emotion-focused or avoidant coping strategy is adopted, burnout is likely to develop (Schaufeli, 2003). Shaddock, Hill and Van Limbeek (1998) found an association between the practice of religion and lower burnout scores. Meltzer and Huckabay (2004) found that nurses, who considered religion to have no importance in their lives, had significantly higher scores on emotional exhaustion than those who considered religion to be important in their lives. Individuals with strong religious beliefs see hope differently than those without such beliefs, which explains their lower emotional exhaustion scores.

Based on the aforementioned discussion, the following hypotheses are formulated:

- Hypothesis 1: Job-related stress predicts emotional exhaustion and depersonalisation, as well as low vigour and dedication of hospital pharmacists.

- Hypothesis 2: Coping strategies predict exhaustion, depersonalisation, and work engagement of hospital pharmacists.

\section{Research design Research approach}

A quantitative research approach was used. A cross-sectional field survey was used to gather the information required to achieve the research objectives (Shaughnessy \& Zechmeister, 1997). This design is suitable to investigate the nature of the relationships between constructs that were of interest in this study.

\section{Research method \\ Participants}

The participants were all hospital pharmacists employed by various private and public sector health facilities in the different provinces of South Africa (Public Health facilities in North West, KwaZulu-Natal and Free State provinces as well as private hospital facilities on a national basis). Random samples were taken of hospital pharmacists according to two strata, namely hospital pharmacies $(N=533)$ and private hospitals $(N=157)$. The sample sizes were 213 (public hospitals) and 63 (private hospitals). A response rate of $72.46 \%$ was achieved, which can be ascribed to call-outs, rotating working schedules and leave as well as difficulties in obtaining permission from the various institutions. Of these only 187 responses $(67.75 \%$ of all the questionnaires distributed) could be utilised. Descriptive information of the sample is given in Table 1.

The sample consisted mainly of Afrikaans-speaking and English-speaking hospital pharmacists $(54.5 \%$ and $34.8 \%)$. They were mostly married (62.7\%), mainly female $(79.1 \%)$ with a mean age of 35.51 years. The average number of years in pharmacy was 12.37 years and the majority of respondents held positions as staff pharmacists (56.2\%).

\section{Measuring battery}

The Maslach Burnout Inventory - Human Services Survey (MBI-HSS) measures respondents' perceived experience of burnout (Maslach \& Jackson, 1996). The MBI-HSS consists of 22 items phrased as statements, which is self-scored on a 7-point frequency scale, ranging from 0 ('never') to 6 ('every day'). The three subscales of the MBI-HSS include emotional exhaustion (nine items, e.g. 'I feel emotionally 
TABLE 1: Characteristics of the participants.

\begin{tabular}{|c|c|c|}
\hline Item & Category & Percentage \\
\hline \multirow[t]{3}{*}{ Language } & Afrikaans & 54.5 \\
\hline & English & 34.8 \\
\hline & Other & 10.7 \\
\hline \multirow[t]{8}{*}{ Position } & $\begin{array}{l}\text { Pharmacy owner or partner and } \\
\text { manager - private hospital sector } \\
\text { (PHS) }\end{array}$ & 1.6 \\
\hline & $\begin{array}{l}\text { Pharmacy owner or partner but not } \\
\text { manager (PHS) }\end{array}$ & 0.5 \\
\hline & $\begin{array}{l}\text { Pharmacy manager but not owner or } \\
\text { partner (PHS) }\end{array}$ & 16.2 \\
\hline & Pharmacy manager - public sector & 8.1 \\
\hline & Pharmacist & 56.2 \\
\hline & Community service pharmacist & 7.6 \\
\hline & Intern & 7 \\
\hline & Other & 2.7 \\
\hline \multirow{5}{*}{$\begin{array}{l}\text { Number of years in } \\
\text { pharmacy }\end{array}$} & Average age of respondents & 35.5 \\
\hline & $\begin{array}{l}\text { Average number of years in } \\
\text { pharmacy }\end{array}$ & 12.4 \\
\hline & $\begin{array}{l}\text { Average number of years in hospital } \\
\text { pharmacy (private sector) }\end{array}$ & 5.1 \\
\hline & $\begin{array}{l}\text { Average number of years in hospital } \\
\text { pharmacy (public sector) }\end{array}$ & 4.5 \\
\hline & $\begin{array}{l}\text { Average number of years in current } \\
\text { position }\end{array}$ & 3.9 \\
\hline \multirow[t]{9}{*}{ Province } & Eastern Cape & 1.1 \\
\hline & Free State & 14.1 \\
\hline & Gauteng & 21.7 \\
\hline & KwaZulu-Natal & 18.5 \\
\hline & Limpopo & 2.7 \\
\hline & Mpumalanga & 2.2 \\
\hline & Northern Cape & 2.2 \\
\hline & North West & 19 \\
\hline & Western Cape & 18.5 \\
\hline \multirow[t]{5}{*}{ Education } & B. Pharm / Dip. Pharm & 89.2 \\
\hline & Hons. Pharm & 1.6 \\
\hline & M. Pharm & 1.6 \\
\hline & M.Sc & 1.6 \\
\hline & Other & 5.9 \\
\hline \multirow[t]{2}{*}{ Gender } & Male & 20.9 \\
\hline & Female & 79.1 \\
\hline \multirow[t]{4}{*}{ Marital status } & Single & 23.2 \\
\hline & Engaged & 10.3 \\
\hline & Married & 62.7 \\
\hline & $\begin{array}{l}\text { Separated, divorced, widow or } \\
\text { widower }\end{array}$ & 3.8 \\
\hline
\end{tabular}

B. Pharm/Dip. Pharm, Bachelor's degree or diploma in Pharmacy; Hons. Pharm, Honour's degree in Pharmacy; M. Pharm, Master's degree in Pharmacy; M.Sc, Master's degree in Science.

drained from my work'), depersonalisation (five items, e.g. 'I feel I treat some recipients as if they were impersonal objects'), and personal accomplishment (eight items, e.g. 'I have accomplished many worthwhile things in this job'). However, the personal accomplishment subscale was not used in this study. Internal consistencies of the MBI-HSS scales are satisfactory with $\alpha$-values ranging from 0.70 to 0.90 (Maslach \& Jackson, 1996). Test-retest coefficients of the MBIHSS range from 0.60 to 0.82 across short periods of up to one month and only drop slightly when longer periods of up to one year are considered (Maslach \& Jackson, 1996).

The Utrecht Work Engagement Scale (UWES) was used to measure levels of engagement (Schaufeli et al., 2002). The concept 'work engagement' includes items referring to vigour (six items, e.g. 'I am bursting with energy in my work'), and dedication (five items, e.g. 'I find my work full of meaning and purpose'). The UWES is scored on a 7-point frequency scale, ranging from 0 ('never') to 6 ('every day'). In terms of internal consistency, reliability coefficients varying from 0.78 to 0.89 have been found in the South African Police Service (Mostert \& Rothmann, 2006).

The Pharmacist Stress Inventory (PSI) was used to measure job stress. The PSI consists of 53 items and was developed to determine the intensity and frequency of job stress experienced by hospital pharmacists (Rothmann \& Malan, 2007). Participants rated each of the 53 statements in terms of perceived intensity of the particular stressor on a scale, ranging from 1 ('low') to 9 ('high'). A construct validity study by Rothmann and Malan (2007) showed that the PSI consists of two factors, namely job demands and lack of resources. Both scales have internal consistencies higher than 0.70 in a sample of hospital pharmacists (Rothmann \& Malan, 2007).

The Coping Orientations to Problems Experienced (COPE) Questionnaire was used to measure coping strategies utilised by participants (Carver et al., 1989). The COPE is a multidimensional 53-item coping questionnaire that indicates the different ways people cope in different circumstances. Exploratory factor analyses showed that the COPE measured four coping strategies of hospital pharmacists. These factors are approach coping ('I try to come up with a strategy about what to do'), seeking social support (e.g. 'I talk to someone to find out more about the situation'), avoidant coping ('I just give up trying to reach my goal') and turning to religion ('I try to find my comfort in my religion'). Response choices were from 1 ('I usually don't do this at all') to 4 ('I usually do this a lot') (Malan, 2005). Malan (2005) found Cronbach alpha coefficients higher than 0.70 for the four factors of the COPE.

\section{Research procedure}

The study was approved by an ethics committee from the Department of Health in South Africa. Participation was voluntary. Objectives of the study were explained to, and written consent obtained from the participants at their place of work where the data collection also took place. Confidentiality and anonymity were assured. The questionnaires were sent by mail to a stratified random sample of hospital pharmacists in South Africa. Completed questionnaires were posted back to the researchers by the respondents.

\section{Statistical analysis}

The statistical analysis was carried out with the SPSSprogram (SPSS Inc., 2003). Cronbach's alpha coefficients were used to assess the reliability of the measuring instruments. Descriptive statistics (e.g. means and standard deviations) were used to analyse the data. Pearson product-moment correlation coefficients were used to specify the relationships between the variables. A cut-off point of 0.30 (medium effect) (Cohen, 1988) was set for the practical significance of correlation coefficients. Multiple regression analyses were 
conducted to determine the percentage of the variance in the dependent variables (burnout and engagement) that is predicted by the independent variables (stress and coping). The effect size in the case of multiple regression is given by the following formula: $f^{2}=R^{2} /\left(1-R^{2}\right)$. A cut-off point of 0.10 (medium effect) was set for the practical significance of $f^{2}$ (Steyn, 1999).

\section{Results}

\section{Descriptive statistics}

The descriptive statistics and alpha coefficients for the various scales are reported in Table 2.

The results in Table 2 indicate that the alpha coefficients for all the scales compare well with the guideline of 0.70 (Nunnally \& Bernstein, 1994). Therefore, the internal consistencies of the various scales used in this study are acceptable.

The intensity, frequency, and severity of stressors for pharmacists in this study are reported in Table 3.

Table 3 shows that the most severe stressors for hospital pharmacists are the unavailability of medicines from suppliers, frequent interruptions, fellow workers not doing their job, inadequate salary and insufficient staff to handle the workload.

\section{Multiple regression analyses}

A series of multiple regression analyses were carried out. (Note: The product-moment correlation coefficients between the MBI-HSS, UWES, PSI and COPE are reported in Table 2.) The results of a multiple regression analysis with job stress (as measured by the PSI) and coping strategies (as measured with the COPE questionnaire) as independent variables, and emotional exhaustion and depersonalisation (as measured by the MBI-HSS) as dependent variables are reported in Table 4.

Table 4 shows that job stress (as measured by the PSI) predicts $23 \%$ of the variance in emotional exhaustion (as measured by the MBI-HSS) $(F=18.41, p<0.01)$. The regression coefficients of the following independent variables are statistically significant $(p<0.01)$ : job demands $(\beta=0.37)$ and lack of resources $(\beta=0.37)$. When coping strategies (as measured by the COPE) were entered into the regression analyses, a statistically significant increase in the $R^{2}(5 \%)$ resulted $(F=9.88, p<0.01)$. Therefore, job stress and coping strategies predict $28 \%$ of the variance in emotional exhaustion $\left(f^{2}>0.35\right.$; practically significant, large effect). The regression coefficients of the following independent variables are statistically significant $(p<0.01)$ : job demands $(\beta=0.33)$, lack of resources $(\beta=0.29)$, avoidant coping $(\beta=0.13)$, and low turning to religion $(\beta=-0.13)$. Therefore, high job demands, lack of resources, applying avoidant coping strategies, and low levels of turning to religion do have an effect on the development of emotional exhaustion in hospital pharmacists.

The results in Table 4 indicate that $12 \%$ of the variance in depersonalisation (as measured by the MBI-HSS) is predicted by job stress (as measured by the PSI). This result was statistically significant $(F=7.94, p<0.01)$. The regression coefficients of the following independent variables is statistically significant $(p<0.05)$ : lack of resources $(\beta=0.23)$. When coping strategies (as measured by the COPE) were entered into the regression analyses, a statistically significant increase in the $R^{2}(5 \%)$ resulted $(F=5.15, p<0.01)$. Therefore, $17 \%$ of the variance in depersonalisation is predicted by job stress and coping strategies $\left(f^{2}>0.10\right.$; practically significant, medium effect). The results showed that the regression coefficients of the following two independent variables are statistically significant $(p<0.01)$ : lack of resources $(\beta=0.23)$ and low approach coping $(\beta=-0.23)$. The lack of resources as well as the lack of an approach coping strategy predicts depersonalisation in South African hospital pharmacists.

The results of a multiple regression analysis with job stress (as measured by the PSI) and coping strategies (as measured with the COPE) as independent variables, and work engagement (as measured by the UWES) as dependent variable are reported in Table 5.

Job stress (as measured by the PSI) negatively predicts $7 \%$ of work engagement (as measured by the UWES; $F=4.87$, $p<0.01)$. The standardised regression coefficient of one

TABLE 2: Descriptive statistics, alpha coefficients and correlations of the MBI, UWES, PSI and COPE.

\begin{tabular}{|c|c|c|c|c|c|c|c|c|c|c|c|c|c|}
\hline Item & & Mean & SD & $\begin{array}{l}\text { Cronbach's } \\
\text { alpha }\end{array}$ & 1 & 2 & 3 & 4 & 5 & 6 & 7 & 8 & 9 \\
\hline 1. & Emotional exhaustion & 18.71 & 10.09 & 0.91 & - & - & - & - & - & - & - & - & - \\
\hline 2. & Depersonalisation & 8.66 & 6.58 & 0.78 & $0.59^{a, c}$ & - & - & - & - & - & - & - & - \\
\hline 3. & Work engagement & 27.3 & 8.55 & 0.93 & $-0.49^{a, b}$ & $-0.38^{a, b}$ & - & - & - & - & - & - & - \\
\hline 4. & Job demands & 94.73 & 25.08 & 0.91 & $0.45^{\mathrm{a}, \mathrm{b}}$ & $0.29^{\mathrm{a}}$ & $-0.27^{a}$ & - & - & - & - & - & - \\
\hline 5. & Pharmacy-specific stressors & 34.12 & 19.39 & 0.87 & 0.11 & $0.17^{\mathrm{a}}$ & -0.1 & $0.43^{\mathrm{a}, \mathrm{b}}$ & - & - & - & - & - \\
\hline 6. & Lack of resources & 112.17 & 24.79 & 0.91 & $0.39^{\mathrm{a}, \mathrm{b}}$ & $0.32^{\mathrm{a}, \mathrm{b}}$ & $-0.20^{\mathrm{a}}$ & $0.65^{\mathrm{a}, \mathrm{c}}$ & $0.42^{\mathrm{a}, \mathrm{b}}$ & - & - & - & - \\
\hline 7. & Approach coping & 58.27 & 7.94 & 0.87 & $-0.23^{a}$ & $-0.27^{a}$ & $0.37^{\mathrm{a}, \mathrm{b}}$ & $-0.26^{a}$ & -0.13 & $-0.17^{a}$ & - & - & - \\
\hline 8. & Seeking social support & 29.88 & 6.44 & 0.86 & 0.02 & 0 & 0.03 & 0.03 & -0.07 & 0.02 & $0.30^{\mathrm{a}, \mathrm{b}}$ & - & - \\
\hline 9. & Avoidant coping & 24.25 & 4.86 & 0.73 & $0.22^{\mathrm{a}}$ & 0.12 & $-0.21^{\mathrm{a}}$ & $0.19^{\mathrm{a}}$ & -0.04 & 0.11 & 0 & $0.15^{\mathrm{a}}$ & - \\
\hline 10. & Turning to religion & 12.82 & 3.47 & 0.91 & -0.09 & -0.02 & 0.03 & 0.12 & 0.07 & 0.05 & $0.23^{a}$ & $0.30^{\mathrm{a}, \mathrm{b}}$ & 0.09 \\
\hline
\end{tabular}

SD, standard deviation; MBI, Maslach Burnout Inventory; UWES, Utrecht Work Engagement Scale; PSI, Pharmacist Stress Inventory; COPE, Coping Orientations to Problems Experienced questionnaire.

a, Correlation is statistically significant at the 0.05 level.

b, Correlation is practically significant $r>0.30$ (medium effect).

c, Correlation is practically significant $r>0.50$ (large effect). 
TABLE 3: Intensity, frequency and severity of stressors for pharmacists.

\begin{tabular}{|c|c|c|c|c|}
\hline Item & Description & Intensity & Frequency & Severity \\
\hline \multicolumn{5}{|c|}{ Factor 1: Job demands } \\
\hline 26 & Meeting targets and deadlines & 5.29 & 4.84 & 25.6 \\
\hline 11 & Assignment of more responsibility & 5.26 & 4.98 & 26.19 \\
\hline 16 & Making critical decisions & 5.48 & 5.05 & 27.67 \\
\hline 25 & Excessive paperwork e.g. administrative duties & 5.57 & 5.38 & 29.97 \\
\hline 7 & Dealing with crisis situations & 6.06 & 4.21 & 25.51 \\
\hline 32 & Dealing with other health care professionals e.g. doctors & 5.27 & 6.75 & 35.57 \\
\hline 9 & Performing tasks not in job description & 4.75 & 3.39 & 16.1 \\
\hline 39 & $\begin{array}{l}\text { Continuous Professional Development activities including } \\
\text { record-keeping }\end{array}$ & 4.43 & 3.40 & 15.06 \\
\hline 31 & Dealing with difficult patients & 5.90 & 4.98 & 29.38 \\
\hline 4 & Assignment of unfamiliar duties & 4.97 & 4.34 & 21.57 \\
\hline 27 & Insufficient personal time (e.g. lunch breaks, coffee/tea breaks) & 4.89 & 4.63 & 22.64 \\
\hline 28 & Covering work for another employee & 5.60 & 5.27 & 29.51 \\
\hline 33 & Ensuring the financial outcomes of the pharmacy & 5.05 & 3.87 & 19.54 \\
\hline 24 & Frequent changes from boring to demanding activities & 4.56 & 4.61 & 21.02 \\
\hline 48 & $\begin{array}{l}\text { Excessive involvement in committee meetings (e.g. infection } \\
\text { control, etc.), making too much demands on pharmacist's time }\end{array}$ & 5.04 & 3.54 & 17.84 \\
\hline 44 & Irrational demands and expectations of clients or patients & 5.79 & 4.58 & 26.52 \\
\hline \multicolumn{5}{|c|}{ Factor 2: Pharmacy-specific stressors } \\
\hline 37 & Slow payment from debtors including medical aids & 2.56 & 0.90 & 2.3 \\
\hline 36 & Paying creditors and settling of pharmacy's accounts & 2.26 & 0.85 & 1.92 \\
\hline 40 & Reconciling medical aid claims & 2.34 & 0.97 & 2.27 \\
\hline 35 & $\begin{array}{l}\text { Competition from other pharmaceutical service providers you } \\
\text { perceive as a possible danger to your business }\end{array}$ & 3.00 & 1.00 & 3.00 \\
\hline 43 & Cash-up and banking & 2.10 & 1.41 & 2.96 \\
\hline 52 & $\begin{array}{l}\text { Biohazard risk posed by administering of substances such as } \\
\text { cytostatics and radiopharmaceuticals }\end{array}$ & 2.93 & 1.18 & 3.46 \\
\hline 53 & $\begin{array}{l}\text { Risk in taking responsibility for the aseptic preparation and } \\
\text { admixing of products for patients e.g. in Neonatal Intensive } \\
\text { Care Unit }\end{array}$ & 2.97 & 1.36 & 4.04 \\
\hline 42 & The management of staff & 4.28 & 4.26 & 18.23 \\
\hline 51 & Encountering labour relations issues with staff & 4.51 & 1.97 & 8.88 \\
\hline \multicolumn{5}{|c|}{ Factor 3: Lack of resources } \\
\hline 29 & Poorly motivated coworkers/colleagues & 6.12 & 5.27 & 32.25 \\
\hline 6 & $\begin{array}{l}\text { Inadequate support by supervisor / tutor / manager / } \\
\text { head office }\end{array}$ & 6.45 & 5.36 & 34.57 \\
\hline 21 & Poor or inadequate supervision / management & 5.52 & 2.93 & 16.17 \\
\hline 18 & Lack of participation in decision-making & 5.34 & 2.87 & 15.33 \\
\hline 14 & Experiencing negative attitudes towards the pharmacy & 5.58 & 4.24 & 23.66 \\
\hline 30 & Conflicts with other departments / divisions in the hospital & 5.7 & 3.82 & 21.77 \\
\hline 10 & Poor or Inadequate equipment & 6.16 & 3.61 & 22.23 \\
\hline 22 & Noisy work area & 4.91 & 3.29 & 16.15 \\
\hline 13 & Difficulty getting along with supervisor / manager / tutor & 5.21 & 1.84 & 9.59 \\
\hline 5 & Coworkers not doing their job & 7.05 & 5.71 & 40.25 \\
\hline 47 & $\begin{array}{l}\text { Uncooperative attitudes of other health professionals } \\
\text { e.g. nursing staff }\end{array}$ & 6.35 & 5.32 & 33.78 \\
\hline 19 & Inadequate salary & 6.95 & 5.61 & 38.99 \\
\hline 15 & Insufficient staff to handle workload & 6.75 & 5.72 & 38.61 \\
\hline 17 & Insult from customer/patient & 6.05 & 2.6 & 15.73 \\
\hline 12 & Periods of inactivity & 4.14 & 1.47 & 6.09 \\
\hline 45 & $\begin{array}{l}\text { Unavailability of medicine stock from suppliers } \\
\text { (e.g. depot) }\end{array}$ & 6.57 & 6.73 & 44.22 \\
\hline 23 & Constant interruptions & 6.28 & 6.95 & 43.65 \\
\hline 8 & Lack of recognition for good work & 6.08 & 4.75 & 28.88 \\
\hline 20 & Competing for advancement & 4.96 & 1.86 & 9.23 \\
\hline
\end{tabular}


TABLE 4: Multiple regression analysis with exhaustion and cynicism as dependent variables.

\begin{tabular}{|c|c|c|c|c|c|c|c|c|c|c|}
\hline \multirow[t]{2}{*}{ Model } & & \multicolumn{2}{|c|}{ Unstandardised Coefficients } & \multirow{2}{*}{$\begin{array}{c}\text { Standardised Coefficients } \\
\text { Beta }\end{array}$} & \multirow[t]{2}{*}{$t$} & \multirow[t]{2}{*}{$p$} & \multirow[t]{2}{*}{$F$} & \multirow[t]{2}{*}{$\boldsymbol{R}$} & \multirow[t]{2}{*}{$\overline{R^{2}}$} & \multirow[t]{2}{*}{$\Delta R^{2}$} \\
\hline & & $B$ & SE & & & & & & & \\
\hline \multicolumn{11}{|c|}{ Exhaustion } \\
\hline \multirow[t]{5}{*}{1} & - & - & - & - & - & - & $18.41^{*}$ & 0.48 & 0.23 & $0.23 *$ \\
\hline & (Constant) & -2.53 & 3.13 & - & -0.81 & 0.42 & - & - & - & - \\
\hline & Job demands & 0.15 & 0.04 & 0.37 & 4.25 & $0.00 *$ & - & - & - & - \\
\hline & Pharmacy-specific stressors & -0.07 & 0.04 & -0.13 & -1.82 & 0.07 & - & - & - & - \\
\hline & Lack of resources & 0.08 & 0.04 & 0.21 & 2.4 & $0.02 *$ & - & - & - & - \\
\hline \multirow[t]{8}{*}{2} & - & - & - & - & - & - & $9.88^{\mathrm{a}, *}$ & 0.53 & 0.28 & $0.05^{*}$ \\
\hline & (Constant) & 3.4 & 6.86 & - & 0.5 & 0.62 & - & - & - & - \\
\hline & Job demands & 0.13 & 0.04 & 0.33 & 3.61 & $0.00^{*}$ & - & - & - & - \\
\hline & Pharmacy-specific stressors & -0.05 & 0.04 & -0.11 & -1.43 & 0.15 & - & - & - & - \\
\hline & Lack of resources & 0.08 & 0.04 & 0.2 & 2.31 & $0.02 *$ & - & - & - & - \\
\hline & Approach coping & -0.15 & 0.09 & -0.11 & -1.61 & 0.11 & - & - & - & - \\
\hline & Seeking social support & 0.09 & 0.11 & 0.06 & 0.8 & 0.43 & - & - & - & - \\
\hline & Turning to religion & -0.39 & 0.2 & -0.13 & -1.95 & $0.05^{*}$ & - & - & - & - \\
\hline \multicolumn{11}{|c|}{ Depersonalisation } \\
\hline \multirow[t]{5}{*}{1} & - & - & - & - & - & - & $7.94 *$ & 0.34 & 0.12 & $0.12^{*}$ \\
\hline & (Constant) & -1.67 & 2.19 & - & -0.76 & 0.45 & - & - & - & - \\
\hline & Job demands & 0.04 & 0.03 & 0.13 & 1.42 & 0.16 & - & - & - & - \\
\hline & Pharmacy-specific stressors & 0.01 & 0.03 & 0.02 & 0.2 & 0.84 & - & - & - & - \\
\hline & Lack of resources & 0.06 & 0.03 & 0.23 & 2.47 & $0.02 *$ & - & & - & - \\
\hline \multirow[t]{7}{*}{2} & - & - & - & - & - & - & $5.15^{\mathrm{b}, *}$ & 0.41 & 0.17 & $0.05^{*}$ \\
\hline & (Constant) & 7.33 & 4.81 & - & 1.53 & 0.13 & - & - & - & - \\
\hline & Job demands & 0.01 & 0.03 & 0.05 & 0.52 & 0.6 & - & - & - & - \\
\hline & Pharmacy-specific stressors & 0.01 & 0.03 & 0.03 & 0.38 & 0.7 & - & - & - & - \\
\hline & Lack of resources & 0.06 & 0.02 & 0.23 & 2.5 & $0.01 *$ & - & - & - & - \\
\hline & Approach coping & -0.19 & 0.06 & -0.23 & -3.07 & $0.00 *$ & - & - & - & - \\
\hline & Seeking social support & 0.06 & 0.08 & 0.06 & 0.78 & 0.43 & - & - & - & - \\
\hline
\end{tabular}

$\mathrm{SE}$, standard error; $p$, probability value; $t, t$-value.

a, $f^{2}>0.35$ - Practically significant (large effect).

b, $f^{2}>0.10$ - Practically significant (medium effect).

$*, p<0.05-$ Statistically significant

TABLE 5: Multiple regression analysis with work engagement as dependent variable.

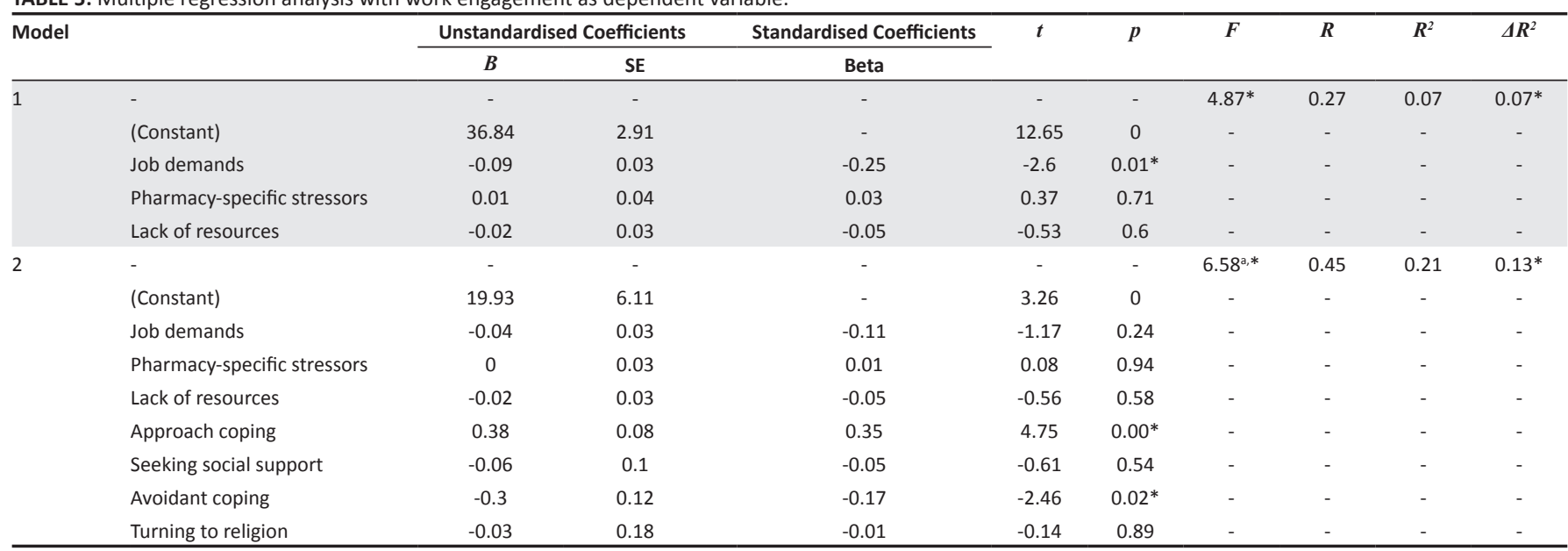

$\mathrm{SE}$, standard error; $p$, probability value; $t, t$-value.

a, $f^{2}>0.10-$ Practically significant (medium effect).

$*, p<0.05$

stressor (namely job demands) is statistically significant $(p<0.01 ; \beta=0.25)$. However, the effect size was small $\left(f^{2}<0.10\right)$. When coping strategies (as measured by the COPE) were entered into the regression analyses, a statistically significant increase in the $R^{2}(13 \%)$ resulted
$(F=6.58, p<0.01)$. This result is practically significant $\left(f^{2}>0.10 ;\right.$ medium effect). The regression coefficients of the following independent variables are statistically significant $(p<0.05)$ : approach coping $(\beta=0.35)$, low avoidant coping $(\beta=-0.17)$. These findings indicate that the application of an 
approach coping strategy as well as the nonutilisation of an avoidant coping strategy leads to increased levels of work engagement.

These findings provide support for the first hypothesis. Jobrelated stress caused by job demands and a lack of resources predicts emotional exhaustion, whilst job-related stress caused by a lack of resources predicts depersonalisation. The findings also provide support for the second hypothesis. Avoidant coping and low levels of turning to religion predict exhaustion, and low approach coping predicts depersonalisation; whilst approach coping and low avoidant coping predict work engagement of hospital pharmacists.

\section{Discussion}

The objectives of this study were to investigate whether jobrelated stress and coping strategies predict the work-related well-being (burnout and work engagement) of hospital pharmacists in South Africa. The results showed that jobrelated stress (as a result of job demands and a lack of job resources), as well as three coping strategies (approach coping, avoidant coping and turning to religion) contributed to various aspects of the work-related well-being of South African hospital pharmacists.

Regarding the negative aspects of work-related well-being, the results showed that job-related stress (as a result of job demands and a lack of resources) contributed strongly to burnout (explaining $23 \%$ and $12 \%$ of the variance in emotional exhaustion and depersonalisation respectively). This finding confirms the results of previous South African studies with police members (e.g. Mostert \& Rothmann, 2006) and nurses (Van der Colff \& Rothmann, 2009). According to Rothmann and Malan (2007), South African hospital pharmacists experience high levels of stress due to their work environment. Pharmacists are unable to perform their expected duties due to a series of factors, namely:

- a lack of the availability of medication

- staff members not doing their job

- insufficient personnel to handle the workload

- inadequate support of supervisors

- uncooperative attitudes of other health care professionals

- inadequate salaries

- inadequate or poor quality equipment (Malan, 2005; Rothmann \& Malan, 2007).

Inexperienced pharmacists, especially younger pharmacists performing their Community Service year are in many instances expected to perform the duties and responsibilities of qualified and registered pharmacists. As they are still lacking the necessary experience, this also contributes to higher stress levels and possible dispensing errors (Matowe et al., 2004). This lack of experience, together with the increasing struggle to source sufficient numbers of qualified pharmacists to handle the workload in hospital pharmacies, will lead to increased levels of stress in the long term (Rothmann \& Malan, 2007).
Hospital pharmacists who experienced stress due to high job demands and a lack of resources showed elevated levels of emotional exhaustion. Stressful job demands include dealing with other health care professionals, excessive paperwork, meeting deadlines, and making critical decisions. Stressful aspects related to a lack of resources include poorly motivated coworkers, inadequate support by supervisor, unavailability of medicine stock from suppliers, constant interruptions, coworkers not doing their job, inadequate salary, and insufficient staff to handle workload. Previous studies (e.g. Mostert \& Rothmann, 2007; Van der Colff \& Rothmann, 2009) confirmed that stressful aspects of the job are associated with emotional exhaustion.

According to Schaufeli (2003), emotional exhaustion is regarded to be the key to the experience of burnout, and the first stage of the burnout process. Emotional exhaustion has consistently been shown to be directly related to high levels of job demands (Shirom, 1989). Quantitative work overload (the perception of too much work to accomplish in the time available) is an important determinant of emotional exhaustion. Hospital pharmacists' attempts to maintain performance standards despite insufficient time and staff may lead to an excessive expenditure of time and emotional energy, which leads to emotional exhaustion. Role conflict is also a job demand that can contribute to emotional exhaustion. Attempts to reconcile conflicting demands may be frustrating and emotionally taxing (Schaufeli, 2003).

This results of this study showed that job-related stress that is caused by a lack of resources is associated with experiences of depersonalisation by hospital pharmacists. Interestingly, job-related stress because of job demands was not statistically significantly associated with depersonalisation. In this study, job-related stress that is caused by a lack of resources consists of stressors such as:

- poorly motivated coworkers

- inadequate support by a supervisor

- lack of participation in decision-making

- experiencing negative attitudes towards the pharmacy

- conflicts with other departments in the hospital

- inadequate equipment

- uncooperative attitudes of other health professionals

- inadequate salary

- insufficient staff to handle workload

- unavailability of medicine stock from suppliers (e.g. depot)

- a lack of recognition for good work.

Although Schaufeli (2003) pointed out that depersonalisation could be regarded as a coping mechanism when a person experiences emotional exhaustion, stress because of a lack of job resources is often linked to depersonalisation. For instance, Cordes and Dougherty (1993) showed in their review on burnout that depersonalisation is a result of a work environment characterised by rigid and controlling administrative practices, and lack of participation. Lack of participation gives employees a feeling of alack of 'control' over critical aspects or demands of their work. Furthermore, 
when an individual perceives environmental conditions as being uncontrollable, a feeling of helplessness or uncertainty ensues. Individuals will depersonalise their relationships with coworkers, clients, or the organisation to cope with such a situation.

The relationship between job stress and burnout (as indicated by emotional exhaustion and depersonalisation) was confirmed in previous studies. Ganster and Schaubroeck (1991) have argued, that burnout is a chronic affective response pattern to stressful work conditions. According to Shirom, burnout is a response to stressors at work (Shirom, 1989). Burnout begins to a great extent as a result of demands, and it intensifies when individuals experience uncertainty where outcomes are important (Cordes \& Dougherty, 1993).

The results of this study showed that it is not only job-related stress that contributes to burnout. Coping strategies employed by hospital pharmacists are also associated with burnout and work engagement. Individuals who tend to avoid stressors (compared with those who are less inclined to avoid stressors) experience higher levels of emotional exhaustion. Denying that a stressor exists, and, or disengaging from the stressful situation (mentally or through their behaviour) seem to result in higher emotional exhaustion. Patton and Goddard (2006) also found an association between an avoidant coping strategy and emotional exhaustion.

Approach coping was negatively associated with depersonalisation in this study. Individuals who cope actively with stressors, plan, and suppress competing activities experienced lower levels of depersonalisation than individuals who are less inclined to use approach coping.

Hospital pharmacists who avoid dealing with problems and who do not find meaning through their religion were more inclined to experience emotional exhaustion. Individuals will be more inclined to turn to religion if they experience more stress (Koenig, 2004). The inverse relationship between burnout and turning to religion was also confirmed in the studies of Shaddock et al. (1998) and Meltzer and Huckabay (2004). Religious beliefs and practices are powerful sources of comfort, hope, and meaning. Religion might be a way to enhance individuals' social support and help them to avoid self-destructive behaviours (Koenig, 2004).

In addition, experiencing job-related stress and not using approach coping strategies seems to contribute to depersonalisation. Although these results confirm the findings of Mills and Huebner (1998), and Schaufeli and Enzmann (1998) they should be interpreted with caution. It is possible that emotional exhaustion leads to avoidant coping and that depersonalisation leads to low approach coping.

Regarding the positive aspects of work-related well-being, the results showed that low stress levels as a result of job demands predicted $7 \%$ of the variance in work engagement, whilst stress as a result of a lack of job resources did not predict work engagement. However, approach coping and low avoidant coping seems to contribute strongly to work engagement.

It can be concluded that job-related stress (because of job pressures and a lack of resources) and coping strategies (low approach coping, high avoidance coping, and low turning to religion) are associated with the burnout of hospital pharmacists. Stressful job demands and coping strategies (high approach coping and low avoidance coping) are associated with work engagement of hospital pharmacists.

Although it remains important to assist individuals whose psychological well-being is affected by their work, both individual and organisational approaches should be used to promote the well-being of hospital pharmacists. Given the accumulating evidence of job demands, a lack of resources and the negative impact thereof on hospital pharmacists, hospital management in both the public and private sectors should intervene to increase the levels of work-related wellbeing of South African hospital pharmacists. Organisations need to address the stressors that carry the main responsibility for the unfavourable work environment and that lead to the development of burnout amongst hospital pharmacists. Furthermore, at an individual level, it is important to focus on and enhance the coping capabilities of hospital pharmacists. As stressful job demands play a central role in burnout, it is necessary to implement preventive organisationally-based strategies to address and mitigate high job demands in order to ensure the effectiveness of pharmaceutical services in hospitals. Preventative organisational-based strategies might avert the implementation of tertiary interventions that are costly and reactive - tertiary level stress management interventions are concerned with the rehabilitation of individuals who suffered from ill health or reduced wellbeing as a result of strain in the workplace.

This was the first study that combined both positive and negative aspects of work-related well-being of hospital pharmacists in South Africa. This study provides important theoretical and practical insights that can be used in managing hospital pharmacists in South Africa. With regard to the limitations of the present study, three aspects can be highlighted. Firstly, due to the fact that the study design was a cross-sectional survey design, it was difficult to prove causal relationships. The use of other designs such as longitudinal designs can assist in establishing causality. A second limitation of this study was that the total study relied merely on self-reporting. This could lead to method variance or disturbance (Schaufeli, Enzmann \& Girault, 1993). Longitudinal research regarding the work-related well-being of hospital pharmacists in South Africa is clearly warranted.

\section{References}

Alsoofi, M.A., Al-Heeti, K.N., \& Alwashli, A. (2000). Burnout and its relationship with job stress and coping with stress for Yemeni teachers. Paper presented at the 28th job stress and coping with stress for Yemeni teachers. Paper
International Congress of Psychology, Stockholm, Sweden.

Barnett, C.W., Hopkins, W.A., \& Jackson, R.A. (1986). Burnout experienced by recent graduates of Mercer University. American Journal of Hospital Pharmacy, 43, 2780-2784. PMid:3799614

Beehr, T.A., Johnson, L.B., \& Nieva, R. (1995). Occupational stress: Coping of police and their spouses. Journal of Organizational Behavior, 16, 3-25. doi:10.1002/ job.4030160104 
Beukes, S. (2002). An opinion on current pharmacy practice and politics. South African Pharmacy Journal, 69, 57-59.

Boschmans, S. (2008). Shirley-Anne shares. SA Pharmaceutical Journal, 75(6), 9.

Brotheridge, C.M., \& Grandey, A.A. (2002). Emotional labor and burnout: Comparing two perspectives of 'people work'. Journal of Vocational Behavior, 60, 17-39. doi:10.1006/jvbe.2001.1815

Callan, V.J. (1993). Individual and organizational strategies for coping with organizational change. Work and Stress, 7, 63-75. doi:10.1080/02678379308257050

Carver, C.S., \& Scheier, M.F. (1996) Self-regulation and its failures. Psychology Inquiry, 7, 32. doi:10.1207/s15327965pli0701_6

Carver, C.S., Scheier, M.F., \& Wientraub, J.K. (1989). Assessing coping strategies: A theoretical based approach. Journal of Personality and Social Psychology, 56, 267-283. doi:10.1037/0022-3514.56.2.267, PMid:2926629

Cavanaugh, S.J. (1989). Nursing turnover: Literature review and methodological critique. Journal of Advanced Nursing, 14, 587-596. doi:10.1111/j.1365-2648.1989. tb01595.x, PMid:2671085

Cohen, J. (1988). Statistical power analysis for the behavioral sciences. (rev. edn.). Orlando, FL: Academic Press.

Cooper, C.L., \& Cartwright, S. (1994). Healthy mind - healthy organization: A proactive approach to occupational stress. Human Relations, 47, 455-471. proactive approach to occupation
doi:10.1177/001872679404700405

Cordes, C.L., \& Dougherty, T.W. (1993). A review and an integration of research on job burnout. The Academy of Management Review, 18, 621-656. doi:10.2307/258593

English, T. (2001). Pharmacist 'dynamic shortage' Detailed by HRSA. Pharmacy Today, 7,1

Folkman, S., \& Lazarus, R.S. (1984). Stress, appraisal and coping. New York: Springer.

Ganster, D.C., \& Schaubroeck, J. (1991). Work, stress and employee health. Journal of Management, 17, 235-271. doi:10.1177/014920639101700202

Golembiewski, R.T., \& Munzenrider, R.F. (1988). Phases of burnout: Development in concepts and applications. New York: Praeger.

Gupchup, G.V., Singhal, P.K., Dole, E.J., \& Lively, B.T. (1998). Burnout in a sample of HMO pharmacists using the Maslach Burnout Inventory. Journal of Managed Care Pharmacy, 4, 495-503.

Health Resources and Services Administration. (2000). The pharmacist workforce: $A$ study of the supply and demand for pharmacists. Rockville, MD: US Department of Health and Human Services, Health Resources and Services Administration.

Jex, S.M., \& Beehr, T.A. (1991). Emerging theoretical and methodological issues in the study of work-related stress. Research in Personnel and Human Resources Management, 9, 311-365.

Kahn, W.A. (1990). Psychological conditions of personal engagement and disengagement at work. Academy of Management Journal, 33, 692-724. doi:10.2307/256287

Knapp, D.A. (2002). Professionally determined need for pharmacy services in 2020 American Journal of Pharmaceutical Education, 66, 421-429.

Knapp, K.K., \& Cultice, J.M. (2007). New pharmacist supply projections: Lowe separation rates and increased graduates boost supply estimates. Journal of the American Pharmaceutical Association, 47, 463-470. doi:10.1331/ JAPhA.2007.07003, PMid:17616492

Koenig, H.G. (2004). Religion, spirituality, and medicine: Research findings and implications for clinical practice. Southern Medical Journal, 97, 1194-1200. doi:10.1097/01.SMJ.0000146489.21837.CE, PMid:15646757

Kowalski, K.C., \& Crocker, P.R.E. (2001). Development and validation of the Coping Function Questionnaire for adolescents in sport. Journal of Sport and Exercise Psychology, 23, 136-155.

Landsbergis, P.A. (1988). Occupational stress among health care workers: A test of the job demands-control model. Journal of Organizational Behavior, 9, 217-239. doi:10.1002/job.4030090303

Lazarus, R.S., \& Folkman, S. (1984). Coping and adaptation. In W.D. Gentry (Ed.), Handbook of behavioral medicine (pp. 282-325). New York: Guilford.

Levert, T. Lucas, M., \& Ortlepp, K. (2000). Burnout in psychiatric nurses: Contributions of the work environment and a sense of coherence. SA Journal of Psychology 30, 36-43.

Malan, A.M. (2005). Burnout and engagement of hospital pharmacists in South Africa. Unpublished doctoral thesis, North-West University, Potchefstroom.

Malan, A.M., Rothmann, S., \& Rothmann, J.C. (2002). Predicting burnout of pharmacists and pharmacist's assistants: A fortigenic approach. Poster presented pharmacists and pharmacist's assistants: A fortige

Maslach, C., Jackson, S.E., \& Leiter, M. (1996). Maslach Burnout Inventory: Manual. (3rd edn.). Palo Alto, CA: Consulting Psychologists Press.

Matowe, L., Duwiejua, M., \& Norris, P. (2004). Is there a solution to the pharmacis brain drain from poor to rich countries? The Pharmaceutical Journal, 272, 98-99.

May, D.R., Gilson, R.L., \& Harter, L.M. (2004). The psychological conditions of meaningfulness, safety and availability and the engagement of the human spirit at work. Journal of Occupational and Organizational Psychology, 77, 11-37. doi:10.1348/096317904322915892
Meltzer, L.S., \& Huckabay, L.M. (2004). Critical care nurses' perceptions of futile care and its effect on burnout. American Journal of Critical Care, 13(3), 202-208. PMid:15149054

Miller, K.I., Ellis, B.H., Zook, E.G., \& Lyles, J.S. (1990). An integrated model of communication, stress, and burnout in the workplace. Communication Research, 17, 200-326. doi:10.1177/009365090017003002

Mills, L.B., \& Huebner, E.S. (1998). A prospective study of personality characteristics, occupational stressors, and burnout in school psychology practitioners. Journal of School Psychology, 36(1), 103-120. doi:10.1016/S0022-4405(97)00053-8

Mostert, K., \& Rothmann, S. (2006). Work-related well-being in the South African PoliceService. Journal of Criminal Justice, 34, 479-491.doi:10.1016/j. jcrimjus.2006.09.003

Mott, D.A., Doucette, W.R., Gaither, C.A., Pedersen, C.A., \& Schommer, J.C. (2004) Pharmacists' attitudes toward worklife: Results from a national survey of pharmacists. Journal of the American Pharmaceutical Association, 44, 326-336. doi:10.1331/154434504323063968, PMid:15191243

Nelson, D.L., \& Simmons, B.L. (2003). Health psychology and work stress: A more positive approach. In J.C. Quick \& L.E. Tetrick (Eds.), Handbook of occupational health psychology (pp. 97-119). Washington, DC: American Psychological Association. doi:10.1037/10474-005

Nunnally, J.C., \& Bernstein, I.H. (1994). Psychometric theory. (3rd edn.). New York: McGraw-Hill.

Patton, W., \& Goddard, R. (2006). Coping with stress in the Australian job network: Gender differences. Journal of Employment Counseling, 43(3), 135-144.

Pienaar, J., \& Rothmann, S. (2003). Coping strategies in the South African Police Service. South African Journal of Industrial Psychology, 29(4), 81-90.

Pretorius, N. (2001). Whose problem is it? South African Pharmacy Journal, 68, 50.

Rothmann, S. (2005). Work-related well-being in South African organisations: What do we know? Paper presented at the 7th Annual Conference of the Employee Assistance Professionals Association of South Africa, Durban.

Rothmann, S., \& Malan, A.M. (2007). Occupational stress of hospital pharmacists in South Africa. International Journal of Pharmacy Practice, 15, 235-242. doi:10.1211/ijpp.15.3.0011

Rothmann, J.C., Rothmann, S., Van Rensburg, S., \& Malan, A.M. (2000). Linking personality preference, career anchors and job satisfaction to pharmacist development. Poster presented at the 4 th International Conference on Pharmaceutical Competence, Ottawa, Canada.

Shaddock, A.J., Hill, M., \& Van Limbeek, C.A.H. (1998). Factors associated with burnout in workers in residential facilities for people with an intellectual disability. Journal of Intellectual and Developmental Disability, 23, 309-318. doi:10.1080/13668259800033791

Schaufeli, W.B. (2003). Past performance and future perspectives of burnout research SA Journal of Industrial Psychology, 29(4), 1-15. doi:10.1002/job.248

Schaufeli, W.B., \& Bakker, A.B. (2004). Job demands, job resources, and their relationship with burnout and engagement: A multi-sample study. Journal of relationship with burnout and eng
Organizational Behaviour, 25, 1-23.

Schaufeli, W.B., \& Enzmann, D. (1998). The burnout companion to study and practice: A critical analysis. London: Taylor \& Francis.

Schaufeli, W.B., Enzmann, D., \& Girault, N. (1993). Measurement of burnout: A review. In W.B. Schaufeli, C. Maslach, \& T. Marek (Eds.), Professional burnout: Recent developments in theory and research (pp. 199-215). Washington, DC: Taylor \& Francis.

Schaufeli, W.B., Salanova, M., González-Romá, V., \& Bakker, A.B. (2002). The measurement of engagement and burnout: A confirmative analytic approach. Journal of Happiness Studies, 3, 71-92. doi:10.1023/A:1015630930326

Shaughnessy, J.J., \& Zechmeister, E.B. (1997). Research methods in psychology (4th edn.). New York: McGraw-Hill.

Shirom, A. (1989). Burnout in work organizations. In C.L. Cooper \& I. Robertson (Eds.) International review of industrial and organizational psychology (pp. 25-48). New York: Wiley.

Spielberger, C.D., Vagg, P.R., \& Wasala, C.F. (2003). Occupational stress: Job pressures and lack of support. In J.C. Quick \& L.E. Tetrick (Eds.), Handbook of occupational health psychology (pp. 185-200). Washington, DC: American Psychological health psychology (pp. 185-200).
Association. doi:10.1037/10474-009

SPSS Inc. (2003). SPSS 12.0 for Windows. Chicago, IL: SPSS Inc.

Steyn, H.S. (1999). Praktiese betekenisvolheid: Die gebruik van effekgroottes. Wetenskaplike bydraes - Reeks B: Natuurwetenskappe Nr. 117. Potchefstroom $\mathrm{PU}$ vir $\mathrm{CHO}$

Van der Colff, J.J., \& Rothmann, S. (2009). Work-related well-being of registered nurses in South Africa. South African Journal of Industrial Psychology, 35, 1-10.

Van Dierendonck, D., Schaufeli, W.B., \& Buunk, B.P. (1993). The evaluation of an individual burnout intervention program: The role of inequity and social support. Journal of Applied Psychology, 83, 392-407. doi:10.1037/0021-9010.83.3.392

Willett, V.J., \& Cooper, C.L. (1996). Stress and job satisfaction in community pharmacy: A pilot study. Pharmaceutical Journal, 256, 94-98. 